\title{
Controle de Plantas daninhas em Arroz Irrigado em Função de Doses de Herbicidas Pré-EMergentes e InÍCIO dA IRRIGAÇÃo ${ }^{1}$
}

\author{
Weed Control in Irrigated Rice as a Function of Pre-Emergence Herbicide Rates and Irrigation \\ Start
}

\author{
CONCENÇO, G. ${ }^{2}$, LOPES, N.F. ${ }^{3}$, ANDRES, A. ${ }^{4}$, MORAES, D.M. ${ }^{3}$, SANTOS, M.Q..$^{5}$, RIEFFEL \\ FILHO, J.A. ${ }^{5}$ e VILELLA, J.V. ${ }^{5}$
}

\begin{abstract}
RESUMO - O objetivo deste trabalho foi avaliar a influência do início da irrigação, associado a doses dos herbicidas penoxsulam e clomazone, no controle de plantas daninhas e rendimento de grãos da cultura do arroz. O experimento foi conduzido em blocos casualizados e parcelas subsubdivididas, com entradas de água (19, 24 e 29 dias após emergência) e os herbicidas penoxsulam $\left(18,36,54\right.$ e $\left.72 \mathrm{~g} \mathrm{ha}^{-1}\right)$ e clomazone $\left(300,400,500\right.$ e $600 \mathrm{~g}^{\text {ha-1) }}$ aplicados em pré-emergência da cultura e das plantas daninhas. Os herbicidas penoxsulam, entre 18 e $72 \mathrm{~g} \mathrm{ha}^{-1}$, e clomazone, entre 400 e $600 \mathrm{~g} \mathrm{ha}^{-1}$, aplicados em pré-emergência na cultura do arroz irrigado, permitiram o início da irrigação até os 29 dias após emergência sem prejuízos no controle de plantas daninhas ou no rendimento de grãos da cultura.
\end{abstract}

Palavras-chave: clomazone, penoxsulam, Oryza sativa.

\begin{abstract}
The objective of this work was to evaluate the behavior of two herbicides, penoxsulam and clomazone, as a function of rates and times of flooding on weed control and grain yield in rice. The trial was conducted in split-split plots and completely randomized block design, with irrigation start (19, 24 and 29 days after emergence), and two herbicides, penoxsulam (18, 36, 54 and $72 \mathrm{~g} \mathrm{ha}^{-1}$ ) and clomazone (300, 400, 500 and $600 \mathrm{~g} \mathrm{ha}^{-1}$ ) applied in pre-emergence of weeds and rice crop. Penoxsulam, between 18 and $72 \mathrm{~g} \mathrm{ha}^{-1}$, and clomazone, between 400 and $600 \mathrm{~g} \mathrm{ha}^{-1}$, applied in pre-emergence in rice crop, allowed irrigation start 29 days after emergence (DAE), without reductions in weed control or grain yield.
\end{abstract}

Keywords: clomazone, penoxsulam, Oryza sativa.

\section{INTRODUÇÃO}

O Brasil destaca-se como grande produtor e consumidor de arroz, produzindo anualmente entre 10 e 11 milhões de toneladas, divididas entre arroz irrigado do tipo longo e arroz de sequeiro do tipo médio. A preferência do consumidor brasileiro é pelo arroz tipo longo, fato que gera, anualmente, insuficiência no abastecimento interno, abrindo, inclusive, espaço para importações (Fleck et al., 2004).
Na ausência de controle de plantas daninhas, a redução na produtividade de grãos da cultura do arroz pode alcançar 80 a 90\% (Andres \& Machado, 2004). O controle químico é o método mais amplamente utilizado, em decorrência da alta eficiência e praticidade. Os herbicidas inibidores da enzima ALS (acetolactato sintase) atuam na biossintese dos aminoácidos de cadeia ramificada valina, leucina e isoleucina (Beyer et al., 1988) e são altamente efetivos, de amplo espectro de

Recebido para publicação em 16..2005 e na forma revisada em 5.5.2006.

Mestrando em Fisiologia Vegetal, UFPel/IB, 96010-900, caixa postal 354, Capão do Leão-RS, <gconcenco@yahoo.com.br>; ${ }^{3}$ Prof. Dr., UFPel/IB, Caixa Postal 354, 96010-900 Capão do Leão-RS; ${ }^{4}$ Pesquisador da área de Herbologia, Embrapa Clima Temperado, Capão do Leão-RS; ${ }^{5}$ Acadêmicos da UFPel/FAEM, estagiários Embrapa Clima Temperado. 
controle, usados em doses reduzidas e de baixa toxicidade ao homem e aos animais (Leite et al., 1998).

O herbicida clomazone, por sua vez, é inibidor da biossíntese de carotenóides, sendo utilizado em pré-emergência ou pós-emergência inicial no controle de várias espécies daninhas na cultura do arroz irrigado (Andres \& Machado, 2004). Devido ao seu mecanismo de ação, quando utilizado em pré-emergência, as plantas sensiveis necessitam emergir para que o herbicida possa exercer sua ação. Apesar de ser eficiente, sua utilização em solos francoarenosos é dependente de dose, sob o risco de causar dano à cultura.

Normalmente, o início da irrigação em arroz está associado ao controle de plantas daninhas. Quando o início da irrigação por inundação ocorrer dentro do período recomendado (15 a 30 dias após a emergência - DAE), o rendimento de grãos normalmente não é afetado, desde que ocorra precipitação regular (Ferraz, 1983). A antecipação do início da irrigação, de 35 para 15 dias após a emergência (DAE) das plantas (Wielewicki et al., 1998), ou o fornecimento de água por maior período de tempo durante o ciclo da cultura do arroz (Del Giudice, 1983) são estratégias que contribuem para o incremento da biomassa seca da parte aérea das plantas, resultando no melhor aproveitamento da radiação solar incidente, podendo incrementar o rendimento de grãos (Back \& Crispim, 2003; Pulver \& Menezes, 2003). O atraso no início da irrigação da cultura do arroz, além de reduzir o rendimento de grãos, pode aumentar de 3\% para $40 \%$ a população de plantas de arroz-vermelho, devido à maior disponibilidade de oxigênio para a germinação das sementes de espécies infestantes (Noldin, 1988).

A presença da lâmina de água pode acarretar diversas respostas fisiológicas das plantas de arroz, como reduzir o perfilhamento, incrementar o alongamento do colmo, aumentar a síntese e resposta ao etileno e estimular o surgimento do aerênquima (Horiguchi, 1995). Mesmo sendo o arroz uma espécie de terras úmidas, suas raízes são tão intolerantes à anoxia como as do milho (Bressan et al., 2004).

O momento de início da irrigação pode estar associado, ainda, a maiores níveis de intoxicação. Normalmente, a imediata irrigação após a aplicação herbicida pode incrementar os danos às plantas da cultura, podendo reduzir a produtividade, fator que influencia a viabilidade do sistema de manejo. As práticas de manejo afetam a capacidade produtiva, que pode ser avaliada diretamente por meio das variáveis conhecidas como componentes do rendimento (Navarro Jr. \& Costa, 2002).

O objetivo deste trabalho foi avaliar a influência do período de irrigação, associado a doses dos herbicidas penoxsulam e clomazone, no controle de plantas daninhas e rendimento de grãos da cultura do arroz irrigado.

\section{MATERIAL E MÉTODOS}

O experimento foi instalado no campo, em Capão do Leão-RS, no ano agrícola 2004/05. A área das subsubparcelas foi de $10 \mathrm{~m}^{2}(2 \mathrm{x}$ $5 \mathrm{~m}) \mathrm{O}$ delineamento experimental foi o de blocos ao acaso com parcelas subsubdivididas, com quatro repetições. As parcelas foram constituídas por três épocas de entrada da água (19, 24 e $29 \mathrm{DAE})$, independentes para cada bloco; as subparcelas, por dois herbicidas (penoxsulam e clomazone); e as subsubparcelas, pelas doses $\left(18,36,54\right.$ e $72 \mathrm{~g} \mathrm{ha}^{-1}$; e $300,400,500$ e $600 \mathrm{~g} \mathrm{ha}^{-1}$, respectivamente). $\mathrm{Na}$ subsubparcela também foi adicionado tratamento sem controle químico ou mecânico, usado como testemunha para as demais avaliações.

O preparo foi realizado no dia 19.10.2004 através de uma aração e duas gradagens, seguidas de duas passadas de rolo, para nivelar e acomodar adequadamente o solo. A semeadura do arroz foi realizada em solo corrigido, no sistema convencional, no dia 26.10.2004, com o cultivar BRS Pelota. A adubação foi realizada em linhas no momento da semeadura, conforme as recomendações da Rede Oficial de Laboratórios de Análise de Solo - ROLAS (1989). A emergência de 50\% das plântulas ocorreu nove dias após a semeadura, e o estabelecimento foi de 400 plantas de arroz por $\mathrm{m}^{2}$.

Os herbicidas foram aplicados um dia após a semeadura, entre 6 e 7h30, com vento em torno de $5 \mathrm{~km} \mathrm{~h}^{-1}$, usando equipamento de pressão constante propelido por $\mathrm{CO}_{2}$ e barra munida de quatro bicos Teejet 110.015 tipo leque, espaçados de 0,5 m. 
Foram determinados a densidade de plantas de angiquinho (Aeschynomene spp.) e o controle de capim-arroz (Echinochloa spp.) e de ciperáceas (Cyperus spp.), avaliados visualmente, em que zero significa ausência de controle e 100 ausência de plantas daninhas na área útil da subsubparcela. Ao final do ciclo foi colhida amostra de $3 \mathrm{~m}^{2}$ em cada subsubparcela, para determinação do rendimento de grãos da cultura, além de 10 panículas à parte, para número de grãos por panícula (subdivididos em grãos cheios e grãos chochos), peso de 1.000 grãos, grãos cheios por panícula e porcentagem de grãos chochos.

Os dados foram submetidos à análise de variância pelo teste $\mathrm{F}$ a $5 \%$, sendo avaliados entrada de água $(\mathrm{E})$, herbicida $(\mathrm{H})$, dose (D), $(E) x(H),(E) x(D),(H) x(D)$ e $(E) x(H) x(D)$. Em caso de significância, foram traçadas regressões lineares, de acordo com o observado na análise de variância.
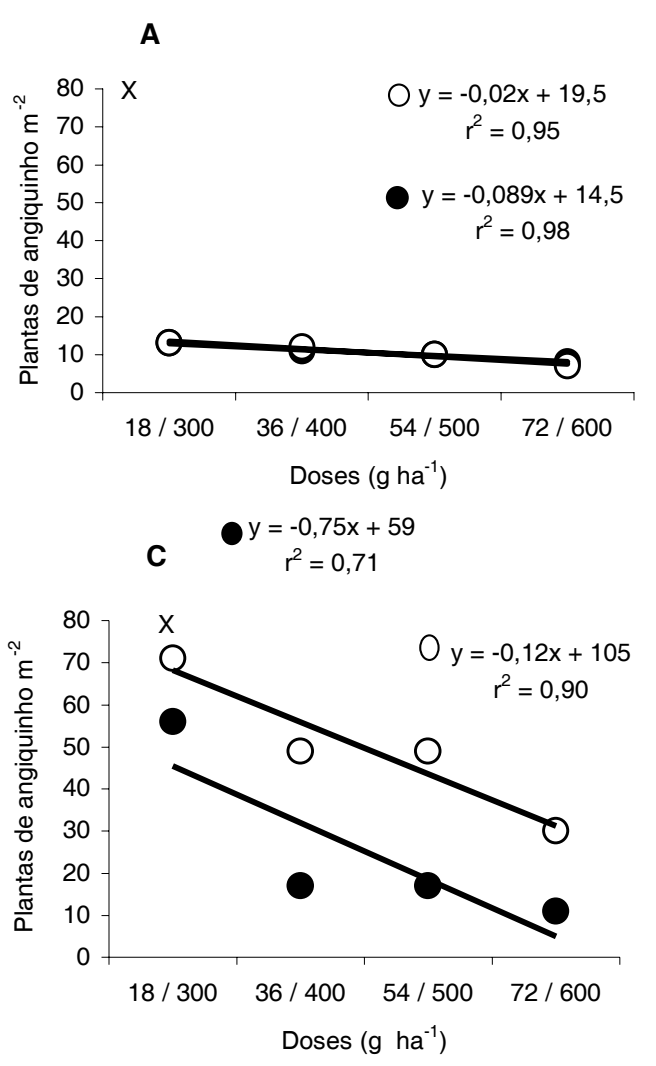

\section{RESULTADOS E DISCUSSÃO}

A densidade de plantas de angiquinho foi reduzida com o incremento na dose de ambos os herbicidas, em todas as épocas de início da irrigação (Figura 1A, B, C). Entretanto, a densidade foi incrementada com o atraso na irrigação, especialmente para o herbicida clomazone (Figura 1D), salientando a importância da entrada de água imediata como forma de complementar o controle químico das plantas daninhas e evitar a emergência de novas plântulas, principalmente em anos de baixa precipitação pluviométrica (Freitas, 2004), além de satisfazer as necessidades de água para o adequado desenvolvimento das plantas de arroz (Horiguchi, 1995). O angiquinho pode ser controlado com bispyribacsodium isolado ou em mistura com clomazone, porém o nível de controle depende, principalmente, da dose empregada, do momento de
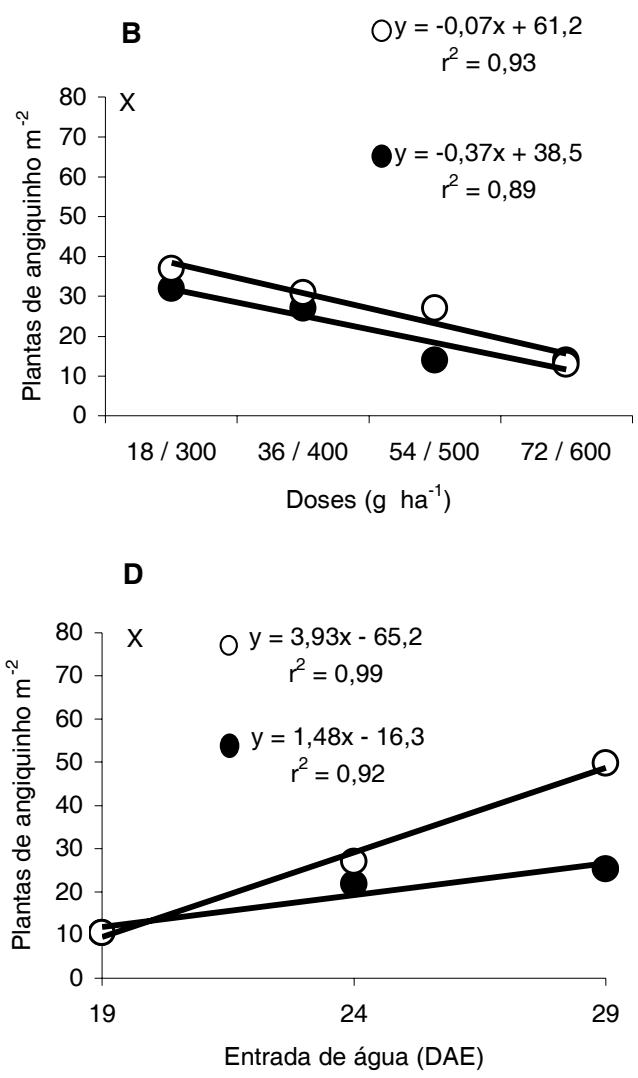

Figura 1 - Densidade de plantas de angiquinho (Aeschynomene spp.) na cultura do arroz irrigado aos 100 dias após emergência (DAE), em função de doses dos herbicidas penoxsulam (•) e clomazone (O), mais testemunha (X), aos 19 (A), 24 (B) e 29 (C) DAE e épocas de início da irrigação (D). Em (A), (B) e (C), cada ponto representa a média de três entradas de água; em (D), cada ponto representa a média de quatro doses dos herbicidas. Embrapa Clima Temperado, 0Capão do Leão-RS, 2004/05. (E)x(H)x(D) $=5 \% ; \mathrm{CV}(\mathrm{a})=29,6 \% ; \mathrm{CV}(\mathrm{b})=30,5 \% ; \mathrm{CV}(\mathrm{c})=27,2 \%$. 
entrada de água após a aplicação e da infestação natural da área (Hatschbach et al., 2003).

É importante ressaltar que as plantas de angiquinho presentes no início da irrigação, aos 19 DAE, de forma geral tinham maior tamanho (dados não mostrados), embora ocorressem em menor densidade (Figura 1A). Como o controle raramente alcança 100\%, algumas plantas acabam sobrevivendo na área (Andres \& Machado, 2004). Provavelmente, as plântulas presentes na primeira época correspondam às sobreviventes aos tratamentos, enquanto o atraso da irrigação permitiu a emergência de nova camada de angiquinho (Firbank \& Watkinson, 1985), incrementando a densidade (Figura 1C). À medida que se atrasou a entrada de água, mais o desempenho dos herbicidas se diferenciou, com melhor efeito de penoxsulam sobre clomazone. O efeito do penoxsulam foi pouco afetado pelo atraso na entrada de água, especialmente nas duas doses maiores (54 e $72 \mathrm{~g} \mathrm{ha}^{-1}$ ), em que geralmente a reinfestação residual de angiquinho se situou entre 5 e 12 plantas por $\mathrm{m}^{2}$ para a maior dose. Já no caso de clomazone, os modelos indicam que, à medida que atrasou a irrigação, a infestação de angiquinho foi aumentando de 8 para 19 e 33 plantas por $\mathrm{m}^{2}$ para a maior dose (Figura 1A, B, C). O grande diferencial entre os dois produtos foi o nível de controle obtido para as maiores doses de ambos quando a entrada de água ocorreu somente aos 29 DAE (Figura 1D).

As plantas de capim-arroz foram controladas eficientemente pelos herbicidas penoxsulam e clomazone quando o início da irrigação ocorreu aos 19 e 24 DAE, em todas as doses testadas (Figura 2A, B). No entanto, com início da irrigação aos $29 \mathrm{DAE}$, a eficiência de controle foi baixa $(<80 \%)$ para clomazone na dose de $300 \mathrm{~g} \mathrm{ha}^{-1}$ (Figura 2C). Logo, quando da utilização de clomazone, é prudente recomendar dose de pelo menos $400 \mathrm{~g} \mathrm{ha}^{-1}$ quando for necessário atrasar a irrigação além dos $24 \mathrm{DAE}$, considerando que o rendimento de grãos se manteve ao redor de 8,3 $\mathrm{t} \mathrm{ha}^{-1}$.

Das plantas daninhas presentes em lavouras de arroz, o capim-arroz é uma das mais estudadas (Griffin \& Harger, 1986), devido principalmente à alta infestação das lavouras e ao potencial de redução no rendimento de grãos (Andrade, 1982). Melo et al. (2004) encontraram densidade de capim-arroz superior a 600 plântulas por metro quadrado após preparo inicial do solo, em área com histórico de cinco anos de cultivo contínuo de arroz irrigado. Andres \& Menezes (1997) verificaram que cada planta de capim-arroz por metro quadrado reduz a produtividade do arroz em $64 \mathrm{~kg} \mathrm{ha}^{-1}$. Além disso, o controle em préemergência (zero DAE) ocasionou rendimento de grãos em torno de $1 \mathrm{t} \mathrm{ha}^{-1}$ superior aos tratamentos com controle aos 10 DAE. Provavelmente, a redução da eficiência do controle de capim-arroz seja mais acentuada nas menores doses e nas épocas de irrigação mais tardias, como foi observado anteriormente por Andres et al. (2003) e Freitas (2004). Os herbicidas penoxsulam e clomazone, usados em préemergência (Figura 2A, B, C), foram eficientes no controle de capim-arroz e, também, na prevenção da reinfestação da lavoura de arroz até os $29 \mathrm{DAE}$, exceto quando o clomazone é usado em dose baixa (300 $\mathrm{g} \mathrm{ha}^{-1}$ ) e a entrada de água ocorre tardiamente (Figura 2C, D).

As ciperáceas possuem alta capacidade de interferência na cultura do arroz quando em altas densidades (Keeley, 1987). De forma geral, os herbicidas inibidores da ALS são eficientes no controle das principais espécies de ciperáceas, Cyperus difformis, C. esculentus, C. ferax e C. iria (Andres \& Machado, 2004). O controle dessas plantas daninhas com penoxsulam independeu da dose ou do início da irrigação, o que significa que ele poderia ser usado com sucesso sobre ciperáceas. O controle se situou ao redor de 97\%, mesmo com o uso da metade da dose recomendada, associado com irrigação tardia. Isso comprova que o penoxsulam é eficiente no controle de Cyperus spp. com aplicação em pré-emergência (Figura 3). O clomazone, por sua vez, não apresentou ação sobre ciperáceas.

O rendimento de grãos não foi influenciado por doses de herbicidas ou por épocas de entrada de água, alcançando valor médio de $8,3 \mathrm{t} \mathrm{ha}^{-1}$, enquanto para a testemunha infestada foi de apenas $0,86 \mathrm{t} \mathrm{ha}^{-1}$ (dados não mostrados). Normalmente, o rendimento de grãos da cultura é reduzido com o atraso da irrigação além do período recomendado, de 15 a 30 dias após a emergência (Gomes et al., 1987, 1999), ou com a redução das doses dos 
herbicidas residuais. Pode ocorrer diminuição de até $20 \%$ no rendimento de grãos do arroz em função do atraso da irrigação de 20 para 35 DAE (Freitas, 2004). Ainda de acordo com este autor, a associação de clomazone e bispyribac-sodium proporciona manutenção nos níveis de rendimento de grãos com o atraso na irrigação. Resultados similares foram obtidos por Hatschbach et al. (2003).

Neste experimento, as condições do ambiente foram favoráveis à ação dos herbicidas, pois, no período compreendido entre aplicação (1 DAE) e última época de início da irrigação (29 DAE), as chuvas foram abundantes e bem distribuídas, mantendo a umidade do solo em nível favorável à ação dos herbicidas. No período entre $29 \mathrm{DAE}$ e final do ciclo ocorreu seca, o que acarretou poucos dias nublados durante o ciclo da cultura, favorecendo a radiação incidente sobre as plantas de arroz e o ganho líquido da fotossintese.

A
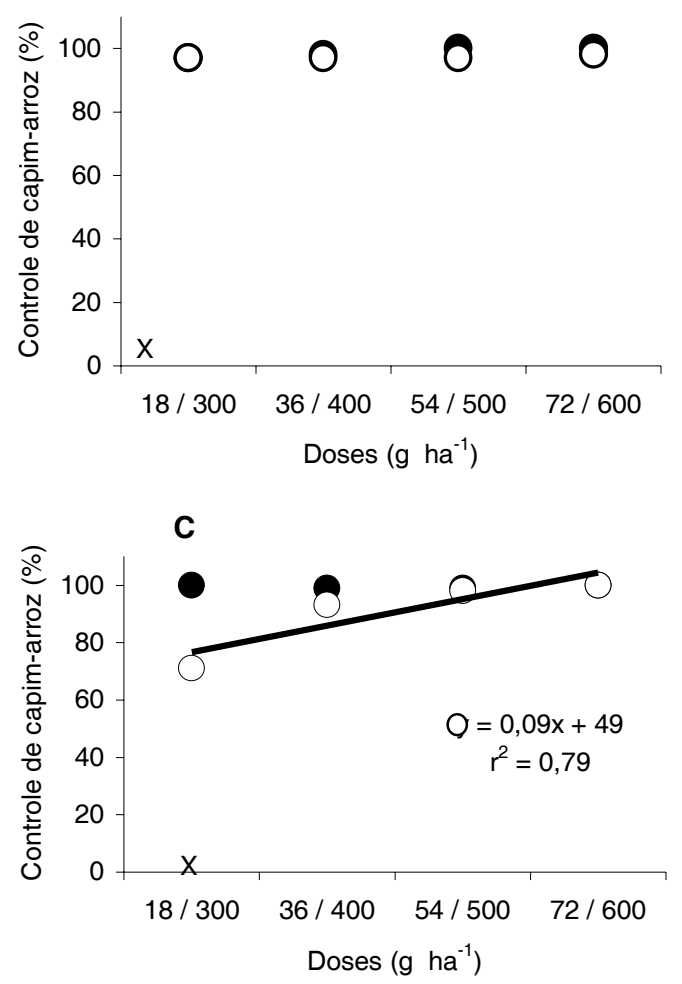

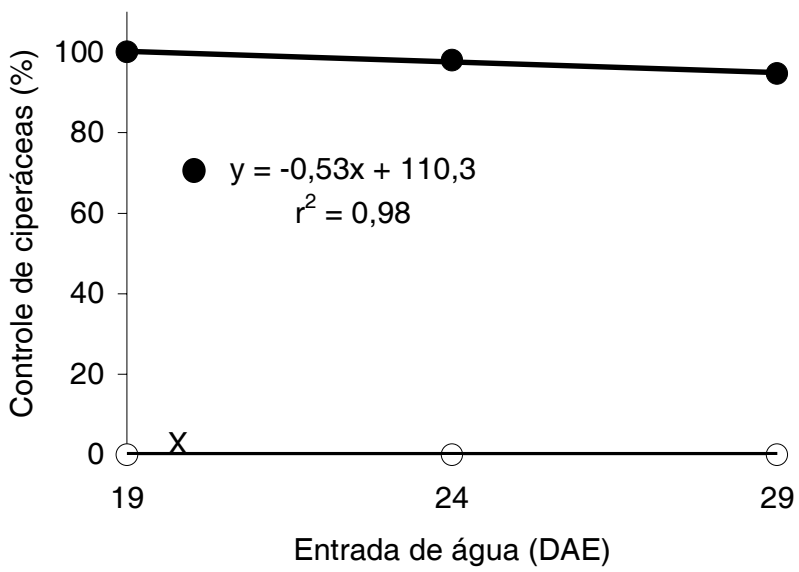

Figura 3 - Controle de ciperáceas (Cyperus spp.) em arroz irrigado aos 100 dias após emergência (DAE), em função dos herbicidas penoxsulam $(\bullet)$ e clomazone $(\mathrm{O})$, mais testemunha $(\mathrm{X})$, e épocas de início da irrigação. Médias das doses. Embrapa Clima Temperado, Capão do Leão-RS, $2004 / 05$. $(\mathrm{E}) \mathrm{x}(\mathrm{H})=5 \% ; \mathrm{CV}(\mathrm{a})=19,6 \% ; \mathrm{CV}(\mathrm{b})=25,2 \%$; $\mathrm{CV}(\mathrm{c})=22,8 \%$.

B
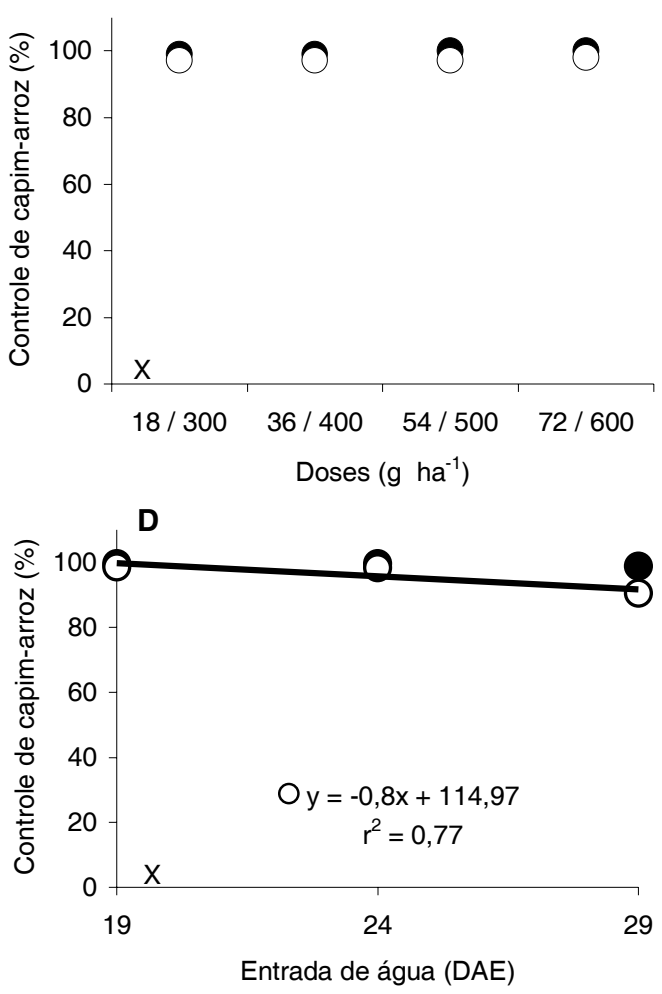

Figura 2 - Controle de capim-arroz (Echinochloa spp.) na cultura do arroz irrigado aos 100 dias após emergência (DAE), em função de doses dos herbicidas penoxsulam (•) e clomazone (O), mais testemunha (X), aos 19 (A), 24 (B) e 29 (C) DAE, e épocas de início da irrigação (D). Em (A), (B) e (C), cada ponto representa a média de três entradas de água; em (D), cada ponto representa a média de quatro doses dos herbicidas. Embrapa Clima Temperado, Capão do Leão-RS, 2004/05. (E)x(H)x(D) $=5 \%$; CV(a) = $7,2 \% ; \mathrm{CV}(\mathrm{b})=4,5 \% ; \mathrm{CV}(\mathrm{c})=6,1 \%$. 
As variáveis número de grãos cheios por panícula, peso de 1.000 grãos, porcentagem de grãos chochos, peso de panículas e rendimento de grãos não mostraram diferenças significativas (dados não mostrados). Ao final do ciclo da cultura, ambos os herbicidas se mostraram sem efeito sobre os componentes determinantes do rendimento de grãos.

Os herbicidas penoxsulam e clomazone, nas doses testadas em pré-emergência na cultura do arroz irrigado, permitem o controle de capim-arroz com início da irrigação até os 29 DAE, exceto para clomazone na dose de $300 \mathrm{~g} \mathrm{ha}^{-1}$; no controle de angiquinho, a entrada precoce de água torna viável a redução da dose herbicida de ambos os produtos, enquanto, à medida que ocorre atraso na irrigação, há necessidade de aumentar as doses; e o penoxsulam proporcionou controle de ciperáceas em todas as doses e entradas de água. Além disso, penoxsulam e clomazone não ocasionaram prejuízos no rendimento de grãos da cultura do arroz irrigado.

\section{LITERATURA CITADA}

ANDRADE, V. A. Efeito da densidade de capim-arroz na produtividade de arroz irrigado. Lav. Arroz., v. 35, p. 30-32, 1982.

ANDRES, A. et al. Eficiência de herbicidas no controle de plantas daninhas em arroz irrigado em função da época de irrigação. In: CONGRESSO BRASILEIRO DE ARROZ IRRIGADO, 3.; REUNIÃO DA CULTURA DO ARROZ IRRIGADO, 25., 2003, Balneário Camboriú. Anais... Itajaí: EPAGRI, 2003. p. 528-530.

ANDRES, A.; MACHADO, S. L. O. Plantas daninhas em arroz irrigado. In: GOMES, A. S.; MAGALHÃES Jr., A. M. (Eds.). Arroz irrigado no sul do Brasil. Brasília: Embrapa Informação Tecnológica, 2004. p. 457-546.

ANDRES, A.; MENEZES, V. G. Rendimento de grãos de arroz irrigado em função de densidade de capim-arroz (Echinochloa crusgalli). In: REUNIÃO DA CULTURA DO ARROZ IRRIGADO, 22., 1997, Balneário Camboriú. Anais... Itajaí: EPAGRI, 1997. p. 429-430.

BACK, A. J.; CRISPIM, J. E. Efeito da estiagem nos componentes de produção do arroz irrigado. In: CONGRESSO BRASILEIRO DO ARROZ IRRIGADO, 3.; REUNIÃO DA CULTURA DO ARROZ IRRIGADO, 25. 2003, Balneário Camboriú. Anais... Itajaí: EPAGRI, 2003. p. $137-139$.

Planta Daninha, Viçosa-MG, v. 24, n. 2, p. 303-309, 2006
BEYER, E. M. et al. Sulfonylureas. In: KEARNEY, P. C.; KAUFMAN, D. D. (Eds.). Herbicides: chemistry, degradation, and mode of action. New York: Marcel-Dekker, 1988. p. $117-190$.

BRESSAN, R. A.; HASEWAGA, P. M.; LOCY, R. D. Fisiologia do estresse. In: TAIZ, L.; ZEIGER, E. (Eds.). Fisiologia vegetal. 3.ed. Porto Alegre: Artmed, 2004. p. 613-643.

DEL GIUDICE, R. M. Absorção cumulativa de nutrientes minerais em duas variedades de arroz (Oryza sativa $\mathrm{L}$.) cultivadas em três diferentes níveis de disponibilidade de água. Campinas: Fundação Cargill, 1983. 110 p.

FERRAZ, E. C. Fisiologia da cultura do arroz. In: SIMPÓSIO SOBRE A CULTURA DO ARROZ DE SEQUEIRO, 1., 1983, Jaboticabal. Anais... Piracicaba: Instituto da Potassa, 1983. p. 77-90.

FIRBANK, L. G.; WATKINSON, A. R. On the analysis of competition within two species mixtures of plants. J. Appl. Ecol., v. 22, p. 503-517, 1985.

FLECK, N. G. et al. Manejo e controle de plantas daninhas em arroz irrigado. In: VARGAS, L.; ROMAN, E. S. (Eds.). Manual de manejo e controle de plantas daninhas. Bento Gonçalves: Embrapa Uva e Vinho, 2004. p. 251-321.

FREITAS, G. D. Desempenho do arroz (Oryza sativa L.) cultivar BRS Pelota e controle de capim-arroz (Echinochloa sp.) submetidos a quatro épocas de entrada de água após aplicação de doses reduzidas de herbicidas. 2004. 54 f. Dissertação (Mestrado em Produção Vegetal) Universidade Federal de Pelotas, Pelotas, 2004.

GOMES, A. S. et al. Manejo de água em arroz irrigado: épocas de início da inundação do solo. In: REUNIÃO DA CULTURA DO ARROZ IRRIGADO, 16., 1987,

Florianópolis. Anais... Balneário Camboriú: EMPASC, 1987. p. 202-206.

GOMES, A. S.; PAUletTO, E. A.; PETRINI, J. A. Arroz irrigado: manejo de água. Pelotas: Embrapa Clima Temperado, 1999. 16 p. (Embrapa Clima Temperado. Circular Técnica, 16).

GRIFFIN, J. L.; HARGER, T. R. Red rice (Oryza sativa) and junglerice (Echinochloa colona) control in solid seeded soybean (Glycine max). Weed Sci., v. 34, p. 582-586, 1986.

HATSCHBACH, M. et al. Eficiência do herbicida bispyribac em mistura com clomazone no controle de Echinochloa crusgalli e Aeschynomene denticulata com entrada de água em duas épocas. In: CONGRESSO BRASILEIRO DE ARROZ IRRIGADO, 3.; REUNIÃO DA CULTURA DO ARROZ IRRIGADO, 25., 2003, Balneário Camboriú. Anais... Itajaí: EPAGRI, 2003. p. 456-458. 
HORIGUCHI, T. Rhizosphere and root functions. In: MATSUO, T. et al. (Eds.) Science of the rice plant: Physiology. Tokyo: Food and Agriculture Research Center, 1995. v. 2. p. 221-248.

KEELEY, P. E. Interference and interaction of purple and yellow nutsedge (Cyperus rotundus and C. esculentus) with crops. Weed Technol., v. 1, p. 74-81, 1987.

LEITE, C. R. F.; ALMEIDA, J. C. V.; PRETE, C. E. C. Aspectos fisiológicos, bioquímicos e agronômicos dos herbicidas inibidores da enzima ALS (AHAS). Londrina: Célio Roberto Ferreira Leite, 1998. 68 p.

MELO, P. T. B. S. et al. Fluxo de emergência de plantas daninhas em áreas de cultivo de arroz irrigado. In: CONGRESSO BRASILEIRO DA CIÊNCIA DAS PLANTAS DANINHAS, 24., 2004, São Pedro. Anais... Londrina: SBCPD, 2004. CD-ROM.

NAVARRO Jr., H. M.; COSTA, J. A. Contribuição relativa dos componentes do rendimento para produção de grãos em soja. Pesq. Agropec. Bras., v. 37, p. 269-274, 2002.
NOLDIN, J. A. Controle de arroz vermelho no sistema de semeadura em solo inundado. Lav. Arroz., v. 41, p. 11-13, 1988.

PULVER, E.; MENEZES, V. G. Importância da radiação solar sobre a produtividade de arroz irrigado. In: CONGRESSO BRASILEIRO DE ARROZ IRRIGADO, 3.; REUNIÃO DA CULTURA DO ARROZ IRRIGADO, 25., 2003, Balneário Camboriú. Anais... Itajaí: EPAGRI, 2003. p. 146-148.

REDE OFICIAL DE LABORATÓRIOS DE ANÁLISE DE SOLO - ROLAS. Recomendação da adubação e calagem para os Estados do Rio Grande do Sul e Santa Catarina. 2.ed. Passo Fundo: SBCS - Núcleo Regional Sul/ EMBRAPA-CNPT, 1989. 128 p.

WIELEWICKI, A.; MARCHEZAN, E.; STORCK, L. Absorção de nutrientes pelo arroz em resposta à calagem e à época de início da irrigação. Ci. Rural, v. 28, p. 17-21, 1998. 